\title{
Predictive Independent Factors for Extrahepatic Metastasis of Hepatocellular Carcinoma Following Curative Hepatectomy
}

\author{
MASAKAZU HASHIMOTO, TSUYOSHI KOBAYASHI, KOHEI ISHIYAMA, KENTARO IDE, \\ MASAHIRO OHIRA, HIROYUKI TAHARA, SHINTARO KURODA, MICHINORI HAMAOKA, \\ HIROSHI IWAKO, SHO OKIMOTO, NARUHIKO HONMYO and HIDEKI OHDAN \\ Department of Gastroenterological and Transplant Surgery, Applied Life Sciences, \\ Institute of Biomedical \& Health Sciences, Hiroshima University, Hiroshima, Japan
}

\begin{abstract}
Aim: The aim of this study was to investigate the prognostic factors associated with extrahepatic metastasis of primary hepatocellular carcinoma (HCC). Patients and Methods: We retrospectively analyzed 559 patients with HCC who underwent curative hepatectomy. We divided the patients into no recurrence (NoR), intrahepatic early recurrence (IHER), intrahepatic late recurrence (IHLR), and extrahepatic recurrence (EHR) groups. We compared the non-metastatic group (IHLR and NoR) with the metastatic group (IHER and EHR) and also compared IHER with EHR to determine risk factors for EHR. Results: There were 252, 163, 109, and 35 patients with NoR, IHER, IHLR, and EHR, respectively. For the EHR group, the independent risk factor was vascular invasion. The EHR group had better liver function and worse tumor factors. Conclusion: Vascular invasion is predictive of extrahepatic metastasis of HCC.
\end{abstract}

Hepatocellular carcinoma (HCC) is the most common primary liver cancers. The majority of patients with HCC develop metastases after curative resection. Most HCC cases develop intrahepatic metastases and intrahepatic recurrence is classified into early and late intrahepatic recurrence because of the differences in the recurrence pattern (1-3). The rate of extrahepatic metastasis is much lower, only $6.7 \%$ to $13.5 \%(4,5)$, but the prognosis of patients with

Correspondence to: Tsuyoshi Kobayashi, MD, Department of Gastroenterological and Transplant Surgery, Applied Life Sciences, Institute of Biomedical \& Health Sciences, Hiroshima University, 1-2-3 Kasumi, Minami-Ku, Hiroshima 734-8557, Japan. Tel: +81 0822575222, Fax: +810822575222, e-mail: tsukoba@hiroshimau.ac.jp

Key Words: Hepatocellular carcinoma, surgical resection, prognosis, extrahepatic recurrence, intrahepatic recurrence. extrahepatic metastasis of HCC is extremely poor because once distant metastases occur, effective treatment is limited.

Adjuvant therapy such as oral chemotherapeutic agents and acyclic retinoid acid after curative resection has been proposed to prevent postoperative recurrence of HCC. Some studies found improvement in tumor-free survival and postoperative survival $(6,7)$, but other studies did not identify any effectiveness of adjuvant therapy (8-10). These studies included all patients after curative resection of HCC but it is important that suitable patients are chosen after consideration of the risk of recurrence for adjuvant therapy. A limited number of studies have reported on the risk factors of intrahepatic early recurrence (IHER), intrahepatic recurrence, and extrahepatic recurrence (EHR).

In the present study, in order to establish indications for adjuvant chemotherapy, we investigated the prognostic factors that predict recurrence after resection of the primary tumor. In addition, we investigated the clinicopathological features related to extrahepatic metastases of HCC versus IHER.

\section{Patients and Methods}

This study retrospectively reviewed 559 consecutive patients with primary HCC who underwent curative hepatic resection in our hospital between January 2003 and December 2012. Curative resection was defined as complete macroscopic removal of the tumor and no exposure of the tumor cells on the cut surface or vascular invasion. These patients were followed-up closely until March 31, 2015.

In the present study, we divided the patients after curative hepatectomy into no recurrence (NoR), IHER, intrahepatic late recurrence (IHLR), and EHR. Among cases of intrahepatic recurrence, it has been reported that most IHERs are caused by intrahepatic metastasis and most cases of IHLR are caused by multicentric carcinogenesis $(2,11)$. Therefore, we defined a 'metastatic' group combining IHER and EHR, and a 'nonmetastatic' group combining NoR and IHLR. In this study, IHER and IHLR were defined as a recurrence within 2 years and more than 2 years after hepatectomy, respectively. 
Clinicopathological variables including age, sex, presence of hepatitis B virus surface antigen (HBs- $\mathrm{Ag}$ ) and hepatitis $\mathrm{C}$ virus antibody (HCV-Ab), presence of diabetes mellitus (DM), preoperative liver function tests, Child-Pugh class, and preoperative alpha-fetoprotein (AFP) and des- $\gamma$-carboxy prothrombin (DCP) levels were obtained. Indications for hepatic resection and the operative method were determined based on tumor progression and Makuuchi's criteria $(12,13)$. Tumor characteristics, according to the Liver Cancer Study Groups of Japan and pathological findings of the resected specimen, were obtained and analyzed (14). Data on liver cirrhosis, microscopic vascular invasion, and intrahepatic metastasis were obtained by performing histological examination of the resected specimens. Surgical complications were classified according to the Clavien-Dindo classification $(15,16)$. This study was approved by the local Institutional Review Board (Epd-1137).

All patients were followed-up for postoperative recurrence with clinical physical examinations, blood chemistry tests, and measurements of the tumor markers including AFP and DCP every month for 2 years and every 3 months thereafter. Patients underwent abdominal ultrasonography (US), dynamic contrast-enhanced computed tomography (CT), and magnetic resonance imaging (MRI) every 3-6 months. Disease-free survival (DFS) was defined as the interval between the hepatectomy and the date of the diagnosis of the first recurrence or the last follow-up. Overall survival (OS) was defined as the interval between hepatectomy and the date of death or the last follow-up.

Categorical variables were compared using the chi-square test. Overall survival (OS) rates were calculated using the Kaplan-Meier method. Differences between curves were assessed according to the log-rank test. Independent prognostic factors were assessed using the multivariate logistic regression model among the variables found to be significant on univariate analysis. Differences of $p<0.05$ were defined as significant. All statistical analyses were performed using the JMP 10 for Windows software package (SAS Institute Japan).

\section{Results}

Clinicopathological features. The median follow-up duration after initial curative hepatectomy was 43.5 months (range $=3.1-131.6$ months). A total of 307 out of 559 patients (54.9\%) experienced recurrence, including 163 (29.2\%) patients with IHER, 109 (19.5\%) patients with IHLR, and 35 (6.3\%) patients with EHR; the other 252 patients had no recurrence. In addition, there were 198 patients in the metastatic group"and 361 patients in the non-metastatic group (Figure 1A). Figure 1B shows the number of patients after hepatectomy in each group.

Comparison of clinicopathological characteristics of patients in the metastatic group with those of the non-metastatic group. The distribution of selected characteristics based on recurrence (metastatic vs. non-metastatic groups) among patients with HCC is shown in Table I. The percentage of patients who had stronger hepatic inflammatory activity (defined based on the serum aspartate aminotransferase [AST] level), poor liver functional reserve (platelet count), higher tumor markers including AFP and DCP, and multiple
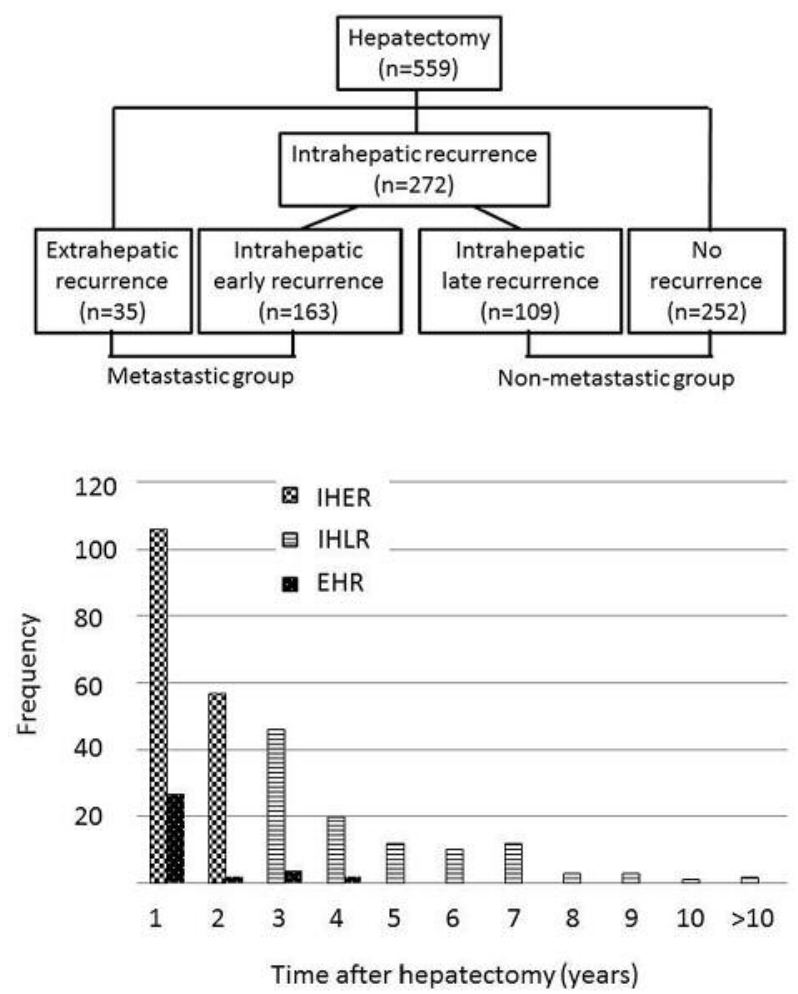

Figure 1. A: Flow chart demonstrating hepatectomy, site, and time patterns of recurrences. B: Number of patients with recurrence of hepatocellular carcinoma after hepatectomy based on the distribution of the time to recurrence after hepatectomy. The intrahepatic early recurrence (IHER) group included the patients with recurrence within 2 years after hepatectomy and the intrahepatic late recurrence (IHLR) group included the patients with recurrence at over 2 years after hepatectomy. EHR: Extrahepatic recurrence.

primary tumors were significantly higher in the metastatic group than in the non-metastatic group.

The OS rate of the non-metastatic group was significantly higher than that of the metastatic group (3- and 5-year survival rates of $92.5 \%$ and $85.4 \%$ versus $68.3 \%$ and $46.6 \%$, respectively) (Figure 2). Table II summarizes the results of the multivariate logistic regression analysis of predictive variables of the metastases after hepatectomy in patients with HCC. Albumin level $<4.0 \mathrm{~g} / \mathrm{dl}(p=0.047)$, serum aspartate aminotransferase (AST) $\geq 40 \mathrm{IU} / 1 \quad(p=0.005)$, vascular invasion $(p<0.001)$, and multiple primary tumors $(p<0.001)$ were independent prognostic factors for metastasis after hepatectomy in patients with HCC.

Comparison of clinicopathological characteristics of patients with HER and IHER. The distributions of selected characteristics based on recurrence site (EHR vs. IHER) among those in the metastatic group are shown in Table III. The percentages of patients who were male, with a higher 
Table I. Comparison of clinicopathological characteristics between non-metastatic and metastatic groups.

\begin{tabular}{|c|c|c|c|}
\hline Characteristic & $\begin{array}{c}\text { Metastatic } \\
\text { group } \\
(\mathrm{n}=198), \mathrm{n}(\%)\end{array}$ & $\begin{array}{l}\text { Non-metastatic } \\
\text { group } \\
(\mathrm{n}=361), \mathrm{n}(\%)\end{array}$ & $p$-Value \\
\hline Age, years & & & 0.859 \\
\hline$<70$ & $107(54.0)$ & $191(52.9)$ & \\
\hline$\geq 70$ & $91(46.0)$ & $170(47.1)$ & \\
\hline Gender & & & 0.616 \\
\hline Male & $149(72.3)$ & $264(73.1)$ & \\
\hline Female & $49(24.8)$ & $97(26.9)$ & \\
\hline HBV surface antigen & & & 0.649 \\
\hline Positive & $34(17.2)$ & $68(18.8)$ & \\
\hline Negative & $164(82.8)$ & $293(81.2)$ & \\
\hline HCV antibody & & & 0.151 \\
\hline Positive & $126(63.6)$ & $207(57.3)$ & \\
\hline Negative & $72(36.4)$ & $154(42.7)$ & \\
\hline Diabetes mellitus & & & 0.768 \\
\hline Yes & $54(27.3)$ & $104(28.8)$ & \\
\hline No & $144(72.7)$ & $257(71.2)$ & \\
\hline Platelet count, $\times 10^{3} / \mathrm{m}^{3}$ & & & 0.037 \\
\hline$<15$ & $134(67.7)$ & $211(58.6)$ & \\
\hline$\geq 15$ & $64(32.3)$ & $149(41.1)$ & \\
\hline Total bilirubin level, $\mathrm{mg} / \mathrm{dl}$ & & & 0.166 \\
\hline$<1.0$ & $136(68.7)$ & $268(74.4)$ & \\
\hline$\geq 1.0$ & $62(31.3)$ & $92(25.6)$ & \\
\hline AST, IU/l & & & $<0.001$ \\
\hline$<40$ & $85(42.9)$ & $242(67.4)$ & \\
\hline$\geq 40$ & $113(57.1)$ & $117(32.6)$ & \\
\hline ALT, IU/1 & & & $<0.001$ \\
\hline$<40$ & $104(52.5)$ & $251(69.7)$ & \\
\hline$\geq 40$ & $94(47.5)$ & $109(30.3)$ & \\
\hline Albumin level, g/dl & & & 0.001 \\
\hline$<4.0$ & $116(58.6)$ & $158(43.9)$ & \\
\hline$\geq 4.0$ & $82(41.4)$ & $202(56.1)$ & \\
\hline Prothrombin time, $\%$ & & & 0.003 \\
\hline$<80$ & $51(25.8)$ & $55(15.3)$ & \\
\hline$\geq 80$ & $147(74.2)$ & $304(84.7)$ & \\
\hline
\end{tabular}

level of HCV antibodies, weaker hepatic inflammatory activity [values of serum AST and alanine aminotransferase (ALT)], had better liver functional reserve (platelet count, albumin level, and prothrombin time), higher tumor marker levels (including DCP), larger tumors, and more microscopic vascular invasion were significantly higher in the EHR group than in the IHER group.

There were no significant differences between the OS rate of the EHR group and that of the IHER group (3- and 5-year survival rates of $50.4 \%$ and $33.4 \%$ versus $72.0 \%$ and $49.4 \%$, respectively) (Figure 3 ). Table IV summarizes the results of the multivariate logistic regression analysis of predictive variables of EHR after hepatectomy in patients with HCC. Vascular invasion $(p=0.047)$ was an independent prognostic factor for EHR after hepatectomy in patients with HCC.

\begin{tabular}{|c|c|c|c|}
\hline Characteristic & $\begin{array}{c}\text { Metastatic } \\
\text { group } \\
(\mathrm{n}=198), \mathrm{n}(\%)\end{array}$ & $\begin{array}{l}\text { Non-metastatic } \\
\text { group } \\
(\mathrm{n}=361), \mathrm{n}(\%)\end{array}$ & $p$-Value \\
\hline ICG-R, \% & & & 0.658 \\
\hline$<15$ & $99(50.3)$ & $189(52.2)$ & \\
\hline$\geq 15$ & $98(49.8)$ & $171(47.5)$ & \\
\hline $\mathrm{AFP}, \mathrm{ng} / \mathrm{ml}$ & & & 0.001 \\
\hline$<20$ & $95(48.2)$ & $225(62.7)$ & \\
\hline$\geq 20$ & $102(51.8)$ & $134(37.3)$ & \\
\hline $\mathrm{DCP}, \mathrm{mAU} / \mathrm{ml}$ & & & 0.034 \\
\hline$<40$ & 85 (42.9) & $188(52.4)$ & \\
\hline$\geq 40$ & $113(57.1)$ & $171(47.6)$ & \\
\hline Background liver & & & 0.563 \\
\hline $\begin{array}{l}\text { Normal liver, } \\
\text { chronic hepatitis }\end{array}$ & $120(64.5)$ & $224(67.1)$ & \\
\hline Liver cirrhosis & $66(35.5)$ & $110(32.9)$ & \\
\hline Number of tumors & & & $<0.001$ \\
\hline single & $107(54.0)$ & $277(76.7)$ & \\
\hline multiple & $91(45.0)$ & $84(23.3)$ & \\
\hline Tumor size, mm & & & 0.307 \\
\hline$<35$ & $124(62.6)$ & $242(67.0)$ & \\
\hline$\geq 35$ & $74(67.0)$ & $119(33.0)$ & \\
\hline Tumor differentiation & & & 0.671 \\
\hline Well & 24 (12.9) & 37 (11.4) & \\
\hline Moderately, poorly & $162(87.1)$ & $287(88.6)$ & \\
\hline Microscopic vascular invasion & & & 0.002 \\
\hline Positive & $51(25.9)$ & 46 (12.9) & \\
\hline Negative & $146(74.1)$ & $312(87.2)$ & \\
\hline Complication* & & & 1.000 \\
\hline$\leq 2$ & $183(92.4)$ & $332(92.0)$ & \\
\hline$\geq 3$ & $15(7.6)$ & $29(8.0)$ & \\
\hline
\end{tabular}

HBV/HCV: Hepatitis B/C virus, AST: aspartate aminotransferase, ALT: alanine aminotransferase, ICG-R: indocyanine green retention test, AFP: $\alpha$-fetoprotein, DCP: Des- $\gamma$-carboxy prothrombin. *Clavian-Dindo classification.

\section{Discussion}

In this study, we investigated the incidence of metastases in a cohort of 559 patients with HCC after curative hepatectomy. The independent risk factors for metastasis after hepatectomy were albumin level $<4.0 \mathrm{~g} / \mathrm{dl}$, AST $\geq 40 \mathrm{IU} / 1$, vascular invasion, and multiple primary tumors. Among the groups with metastasis, the independent risk factor for the EHR group was vascular invasion. The EHR group had better liver function and worse tumor factors than the IHER group.

In this study, the metastatic group (IHER and EHR) also had worse tumor factors but better liver functional reserve than the non-metastatic group (IHLR and NoR). This result is consistent with the results of other studies $(1,2,17,18)$. Prior studies have identified risk factors for early recurrence, 

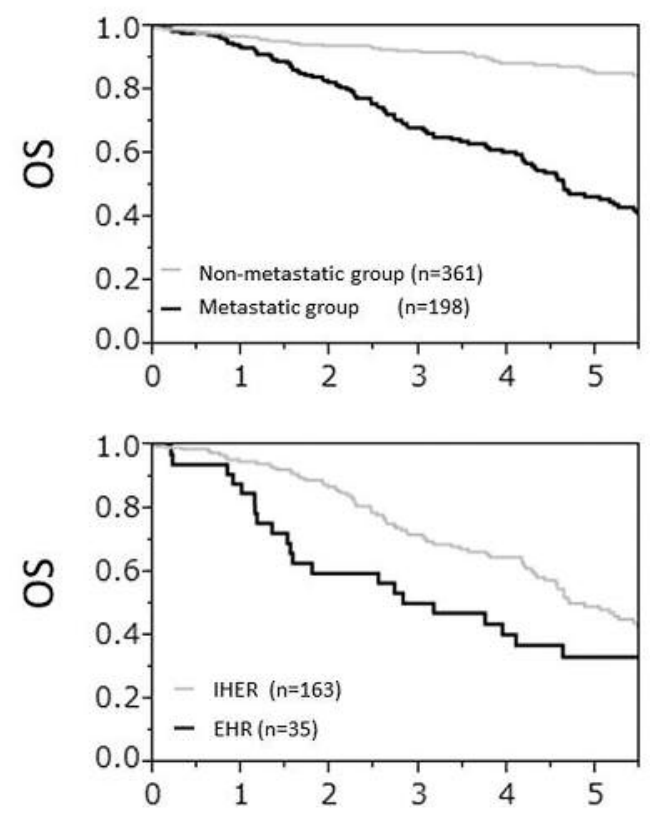

Time after hepatectomy (years)

Figure 2. A: Prognosis of the patients in the non-metastatic group [no recurrence $(N o R)+$ intrahepatic late recurrence $(I H L R)]$ and the metastatic group intrahepatic early recurrence $($ IHER $)+$ extrahepatic recurrence (EHR)] who underwent liver resection. Kaplan-Meier curves of overall survival $(O S)$ after hepatectomy. OS rates of the nonrecurrence group at 3 and 5 years $(92.5 \%$ and $85.4 \%$, respectively) were significantly higher than those of the metastatic group at 3 and 5 years $(68.3 \%$ and $46.6 \%$, respectively) $(p<0.001)$. B: Prognosis of the patients in the IHER group and the EHR group who underwent liver resection. Kaplan-Meier curves of the OS rates after hepatectomy. OS rates of the IHER group at 3 and 5 years $(72.0 \%$ and $49.4 \%$, respectively) were significantly higher than those of the HER group at 3 and 5 years (50.4\% and 33.4\%, respectively) $(p=0.1348)$.

including vascular invasion, multiple tumors, high DCP level, high AFP level, intrahepatic metastasis, and Milan criteria status. Recently, Schulze et al. reported that circulating tumor cells had an important function in extrahepatic metastasis and macroscopic angioinvasion (19) and Fan et al. (20) reported that blood cancer stem cell density predicted recurrence after hepatectomy in HCC.

We investigated the pattern of recurrence among those with early recurrence, because the early recurrence of HCC after curative hepatectomy indicates a poor prognosis. Moreover, predicting the pattern of metastasis in the early recurrence group is important for selecting the appropriate treatment strategy. Our study showed that tumor factors were worse in the EHR group than in the IHER group, and in particular, vascular invasion was significantly worse than in the IHER group. Seanthan Senthilnathan et al. reported that
Table II. Multivariate logistic regression analysis of variables predictive of metastasis after hepatectomy.

\begin{tabular}{lccc}
\hline Factor & $\begin{array}{c}\text { Relative } \\
\text { risk }\end{array}$ & $\begin{array}{c}95 \% \\
\text { Confidence } \\
\text { interval }\end{array}$ & $p$-Value \\
\hline $\mathrm{AFP} \geq 20 \mathrm{ng} / \mathrm{ml}$ & 1.16 & $0.78-1.72$ & 0.463 \\
$\mathrm{ALT} \geq 40 \mathrm{IU} / \mathrm{l}$ & 1.24 & $0.75-2.04$ & 0.390 \\
$\mathrm{Platelet}$ count $\geq 15 \times 10^{3} / \mathrm{m}^{3}$ & 1.45 & $0.94-2.19$ & 0.094 \\
$\mathrm{DCP} \geq 40 \mathrm{mAU} / \mathrm{ml}$ & 1.42 & $0.94-2.12$ & 0.091 \\
Prothrombin time $<80 \%$ & 1.52 & $093-2.46$ & 0.089 \\
Albumin level $<4.0 \mathrm{~g} / \mathrm{dl}$ & 1.51 & $1.00-2.27$ & 0.047 \\
$\mathrm{AST} \geq 40 \mathrm{IU} / 1$ & 1.43 & $1.24-3.39$ & 0.005 \\
Vascular invasion Positive & 2.53 & $1.53-4.23$ & $<0.001$ \\
Number of tumors; multiple & 2.71 & $1.81-4.05$ & $<0.001$ \\
\hline
\end{tabular}

AFP: $\alpha$-Fetoprotein, ALT: alanine aminotransferase, DCP: des- $\gamma$ carboxy prothrombin, AST: aspartate aminotransferase.

multivariate analyses in HCC identified age $<65$ years, AFP $>200 \mathrm{ng} / \mathrm{ml}$, and vascular invasion as risk factors for extrahepatic metastasis (21). Yang et al. reported that extrahepatic metastases were more common in patients with vascular invasion, intrahepatic metastases, and more advanced tumor stage (22). Our results are consistent with these regarding the pattern of recurrence among those with early recurrence.

Interestingly, our study also showed that liver function in the EHR group tended to be better than that in the IHER group. As Table III shows, the EHR group had a higher platelet count, albumin level and prothrombin time, and lower AST and ALT levels. Liver function related to the pattern of metastasis for patients with HCC has rarely been reported. A few clinical studies that focused on the background of the liver in patients with distant metastasis of HCC have been reported. Ochiai et al. reported that the clinicopathologic features of the EHR group had better indocyanine green retention test and the rate of cirrhosis was lower compared with the IHER group (23). Li Jun et al. showed that the liver function of the EHR group was better than that of the no-HER group (24). Our results for liver function in patients with distant metastasis of $\mathrm{HCC}$ are consistent with these results.

After we reviewed these results, we considered that one of the causes is related to the difference in liver microenvironment arising from liver inflammation. Mikuriya et al. reported that liver with hepatitis and liver cirrhosis promoted metastasis by releasing inflammatory cytokines from hepatic stellate cells (25). Nishikawa et al. reported oxygen radicals promoted metastasis and cancer invasion (26). Agopian et al. reported that 117 patients were found to have recurrent HCC among 865 liver transplant patients, the most frequent sites being the lungs (59\%), abdomen/pelvis 
Table III. Comparison of clinicopathological characteristics between extrahepatic recurrence (EHR) and intrahepatic early recurrence (IHER) groups.

\begin{tabular}{|c|c|c|c|}
\hline Characteristic & $\begin{array}{c}\text { EHR } \\
(\mathrm{n}=35), \\
\mathrm{n}(\%)\end{array}$ & $\begin{array}{c}\text { IHER } \\
(\mathrm{n}=163) \\
\mathrm{n}(\%)\end{array}$ & $p$-Value \\
\hline Age, years & & & 0.461 \\
\hline$<70$ & $21(60.0)$ & $86(52.6)$ & \\
\hline$\geq 70$ & $14(40.0)$ & $77(47.2)$ & \\
\hline Gender & & & 0.016 \\
\hline Male & $32(91.4)$ & $117(71.8)$ & \\
\hline Female & $3(8.6)$ & $46(28.2)$ & \\
\hline HBV surface antigen & & & 0.145 \\
\hline Positive & $9(25.7)$ & $25(15.3)$ & \\
\hline Negative & $26(74.3)$ & $138(84.7)$ & \\
\hline HCV antibody & & & 0.001 \\
\hline Positive & $13(37.1)$ & $113(69.3)$ & \\
\hline Negative & $22(62.8)$ & $50(30.7)$ & \\
\hline Diabetes mellitus & & & 0.093 \\
\hline Yes & $14(40.0)$ & $40(24.5)$ & \\
\hline No & $21(60.0)$ & $123(75.5)$ & \\
\hline Platelet count, $\times 10^{3} / \mathrm{m}^{3}$ & & & 0.005 \\
\hline$<15$ & $15(45.7)$ & $118(72.4)$ & \\
\hline$\geq 15$ & $19(54.3)$ & $45(27.6)$ & \\
\hline Total bilirubin level, $\mathrm{mg} / \mathrm{dl}$ & & & 1.000 \\
\hline$<1.0$ & $24(68.6)$ & $112(68.7)$ & \\
\hline$\geq 1.0$ & $11(31.4)$ & $51(31.3)$ & \\
\hline AST, IU/1 & & & 0.001 \\
\hline$<40$ & $24(68.6)$ & $61(37.4)$ & \\
\hline$\geq 40$ & $11(31.4)$ & $102(62.6)$ & \\
\hline ALT, IU/1 & & & 0.016 \\
\hline$<40$ & $25(71.4)$ & 79 (48.5) & \\
\hline$\geq 40$ & $10(28.6)$ & $84(51.5)$ & \\
\hline Albumin level, g/dl & & & 0.008 \\
\hline$<4.0$ & $13(37.1)$ & $103(63.2)$ & \\
\hline$\geq 4.0$ & $22(62.9)$ & $60(36.8)$ & \\
\hline Prothrombin time, $\%$ & & & 0.034 \\
\hline$<80$ & $4(11.4)$ & $47(28.8)$ & \\
\hline$\geq 80$ & $31(88.5)$ & $116(71.2)$ & \\
\hline
\end{tabular}

\begin{tabular}{|c|c|c|c|}
\hline Characteristic & $\begin{array}{c}\text { EHR } \\
(\mathrm{n}=35), \\
\mathrm{n}(\%)\end{array}$ & $\begin{array}{c}\text { IHER } \\
(\mathrm{n}=163), \\
\mathrm{n}(\%)\end{array}$ & $p$-Value \\
\hline ICG-R, \% & & & 0.187 \\
\hline$<15$ & $21(61.8)$ & $78(47.6)$ & \\
\hline$\geq 15$ & $13(38.2)$ & $85(52.2)$ & \\
\hline AFP, ng/ml & & & 1.000 \\
\hline$<20$ & $17(48.6)$ & $78(48.2)$ & \\
\hline$\geq 20$ & $18(51.4)$ & $84(51.9)$ & \\
\hline $\mathrm{DCP}, \mathrm{mAU} / \mathrm{ml}$ & & & 1.000 \\
\hline$<40$ & $8(22.9)$ & $77(47.2)$ & \\
\hline$\geq 40$ & $27(77.1)$ & $86(52.8)$ & \\
\hline Background liver & & & 0.072 \\
\hline $\begin{array}{l}\text { Normal liver, } \\
\text { chronic hepatitis }\end{array}$ & $26(78.8)$ & 94 (61.4) & \\
\hline Liver cirrhosis & $7(21.2)$ & $59(38.6)$ & \\
\hline Number of tumors & & & 0.713 \\
\hline Single & $20(57.1)$ & $87(53.4)$ & \\
\hline Multiple & $15(42.9)$ & $76(46.6)$ & \\
\hline Tumor size, $\mathrm{mm}$ & & & $<0.001$ \\
\hline$<35$ & $12(34.3)$ & $112(68.7)$ & \\
\hline$\geq 35$ & $23(65.7)$ & $51(31.3)$ & \\
\hline Tumor differentiation & & & 0.085 \\
\hline Well & $1(2.9)$ & $23(15.1)$ & \\
\hline Moderately, Poorly & $22(97.1)$ & $129(84.9)$ & \\
\hline Microscopic vascular invasion & & & $<0.001$ \\
\hline Positive & $19(54.3)$ & $32(19.8)$ & \\
\hline Negative & $16(45.7)$ & $130(80.3)$ & \\
\hline Complication* & & & 0.310 \\
\hline$\leq 2$ & 31 (88.6) & $152(93.3)$ & \\
\hline$\geq 3$ & $4(11.4)$ & $11(6.8)$ & \\
\hline
\end{tabular}

HBV/HCV: Hepatitis B/C virus, AST: aspartate aminotransferase, ALT: alanine aminotransferase, ICG-R: indocyanine green retention test, AFP: $\alpha$-fetoprotein, DCP: Des- $\gamma$-carboxy prothrombin.*Clavian-Dindo classification.

$(38 \%)$, and the liver (35\%) (27). Taken together with circulating tumor cells, the presence of which is an independent risk factor for metastasis (19), these results may indicate that implantation and metastasis are more likely to occur because of inflammatory cytokines in patients with poor liver function; in contrast, implantation and metastasis in a healthier liver is difficult and therefore recurrence appears as distant metastasis. The possibility cannot be excluded that tumors from multicentric carcinogenesis are included in cases of early recurrence and HCC is less likely to arise from normal liver than HCC developing in the setting of hepatitis and liver cirrhosis. In any case, based on these results, we propose that it is necessary to pay more attention to the possibility of extrahepatic recurrence than intrahepatic recurrence in the case of patients at high risk of recurrence with good liver function.
Table IV. Multivariate logistic regression analysis of variables predictive of extrahepatic metastasis after hepatectomy.

\begin{tabular}{lccc}
\hline Factor & $\begin{array}{c}\text { Relative } \\
\text { risk }\end{array}$ & $\begin{array}{c}95 \% \\
\text { Confidence } \\
\text { interval }\end{array}$ & $p$-Value \\
\hline ALT $<40 \mathrm{IU} / 1$ & 1.44 & $0.47-4.41$ & 0.522 \\
$\mathrm{HCV}$ antibody-negative & 1.38 & $0.53-3.54$ & 0.501 \\
$\mathrm{DCP} \geq 40 \mathrm{mAU} / \mathrm{ml}$ & 1.51 & $0.57-4.21$ & 0.404 \\
Albumin level $\geq 4.0 \mathrm{~g} / \mathrm{dl}$ & 1.54 & $0.57-4.21$ & 0.372 \\
Male sex & 2.18 & $0.61-10.37$ & 0.241 \\
AST $<40 \mathrm{IU} / 1$ & 2.12 & $0.72-6.55$ & 0.172 \\
Prothrombin time $\geq 80 \%$ & 2.58 & $0.81-10.17$ & 0.113 \\
Tumor size $\geq 35 \mathrm{~mm}$ & 2.35 & $0.93-6.10$ & 0.069 \\
Vascular invasion & 2.50 & $1.01-6.20$ & 0.047 \\
\hline
\end{tabular}

ALT: Alanine aminotransferase, HCV: hepatitis C virus DCP: des- $\gamma$ carboxy prothrombin, AST: aspartate aminotransferase. 
Our search of the literature revealed the strategy used for applying adjuvant chemotherapy after hepatectomy for advanced HCC. Generally, sorafenib has been shown to extend survival in patients with advanced disease (28). Several studies have reported the survival benefits of hepatic arterial infusion chemotherapy (HAIC) for advanced HCC $(29,30)$. In general, HAIC is thought to be more effective in cases of intrahepatic metastasis in HCC and sorafenib in cases of distant metastasis. Based on the results of our study, sorafenib for adjuvant chemotherapy might be a better treatment than HAIC for patients who have good liver function and a high metastatic risk based on the presence of factors such as vascular invasion.

This study has several limitations to consider. Firstly, it was a single-institution study and was retrospective in nature. Secondly, we divided intrahepatic recurrence into two groups (IHER and IHLR) for distinguishing between multicentric carcinogenesis and metastasis from a primary tumor. However, it is difficult to differentiate these two types accurately, and tumors from multicentric carcinogenesis may have been included in our IHER group.

In conclusion, we found the independent risk factors of metastasis after hepatectomy to be an albumin level $<4.0 \mathrm{~g} / \mathrm{dl}$, AST $\geq 40 \mathrm{IU} / \mathrm{l}$, vascular invasion, and multiple primary tumors. For the metastatic group, we found the independent risk factor of EHR to be vascular invasion. Interestingly, the EHR group had worse tumor factors but better liver functional reserve than did the IHER group.

\section{References}

1 Hayashi M, Shimizu T, Hirokawa F, Inoue Y, Komeda K, Asakuma M, Miyamoto Y, Takeshita A, Shibayama Y and Tanigawa N: Clinicopathological risk factors for recurrence within one year after initial hepatectomy for hepatocellular carcinoma. Am Surg 77: 572-578, 2011.

2 Imamura H, Matsuyama Y, Tanaka E, Ohkubo T, Hasegawa K, Miyagawa S, Sugawara Y, Minagawa M, Takayama T, Kawasaki $\mathrm{S}$ and Makuuchi M: Risk factors contributing to early and late phase intrahepatic recurrence of hepatocellular carcinoma after hepatectomy. J Hepatol 38: 200-207, 2003.

3 Hirokawa F, Hayashi M, Asakuma M, Shimizu T, Inoue Y and Uchiyama K: Risk factors and patterns of early recurrence after curative hepatectomy for hepatocellular carcinoma. Surg Oncol 25: 24-29, 2016.

4 Chan KM, Yu MC, Wu TJ, Lee CF, Chen TC, Lee WC and Chen MF: Efficacy of surgical resection in management of isolated extrahepatic metastases of hepatocellular carcinoma. World J Gastroenterol 15: 5481-5488, 2009.

5 Taketomi A, Toshima T, Kitagawa D, Motomura T, Takeishi K, Mano Y, Kayashima H, Sugimachi K, Aishima S, Yamashita Y, Ikegami T, Gion T, Uchiyama H, Soejima Y, Maeda T, Shirabe $\mathrm{K}$ and Maehara Y: Predictors of extrahepatic recurrence after curative hepatectomy for hepatocellular carcinoma. Ann Surg Oncol 17: 2740-2746, 2010.
6 Yamamoto M, Arii S, Sugahara K and Tobe T: Adjuvant oral chemotherapy to prevent recurrence after curative resection for hepatocellular carcinoma. Br J Surg 83: 336-340, 1996.

7 Xia Y, Qiu Y, Li J, Shi L, Wang K, Xi T, Shen F, Yan Z and Wu M: Adjuvant therapy with capecitabine postpones recurrence of hepatocellular carcinoma after curative resection: a randomized controlled trial. Ann Surg Oncol 17: 3137-3144, 2010.

8 Ono T, Nagasue N, Kohno H, Hayashi T, Uchida M, Yukaya H and Yamanoi A: Adjuvant chemotherapy with epirubicin and carmofur after radical resection of hepatocellular carcinoma: a prospective randomized study. Semin Oncol 24: S6-18-S16-25, 1997.

9 Hasegawa K, Takayama T, Ijichi M, Matsuyama Y, Imamura H, Sano K, Sugawara Y, Kokudo N and Makuuchi M: Uraciltegafur as an adjuvant for hepatocellular carcinoma: a randomized trial. Hepatology 44: 891-895, 2006.

10 Bruix J, Takayama T, Mazzaferro V, Chau GY, Yang J, Kudo M, Cai J, Poon RT, Han KH, Tak WY, Lee HC, Song T, Roayaie S, Bolondi L, Lee KS, Makuuchi M, Souza F, Berre MA, Meinhardt $G$ and Llovet JM: Adjuvant sorafenib for hepatocellular carcinoma after resection or ablation (STORM): a phase 3, randomised, double-blind, placebo-controlled trial. The Lancet Oncology 16: 1344-1354, 2015.

11 Poon RT, Fan ST, Ng IO, Lo CM, Liu CL and Wong J: Different risk factors and prognosis for early and late intrahepatic recurrence after resection of hepatocellular carcinoma. Cancer 89: 500-507, 2000.

12 Makuuchi M, Kosuge T, Takayama T, Yamazaki S, Kakazu T, Miyagawa $\mathrm{S}$ and Kawasaki S: Surgery for small liver cancers. Semin Surg Oncol 9: 298-304, 1993.

13 Itamoto T, Katayama K, Nakahara H, Tashiro H and Asahara T: Autologous blood storage before hepatectomy for hepatocellular carcinoma with underlying liver disease. Br J Surg 90: 23-28, 2003.

14 Minagawa M, Ikai I, Matsuyama Y, Yamaoka Y and Makuuchi M: Staging of hepatocellular carcinoma: assessment of the Japanese TNM and AJCC/UICC TNM systems in a cohort of 13,772 patients in Japan. Ann Surg 245: 909-922, 2007.

15 Dindo D, Demartines N and Clavien PA: Classification of surgical complications: a new proposal with evaluation in a cohort of 6336 patients and results of a survey. Ann Surg 240: 205-213, 2004.

16 Clavien PA, Barkun J, de Oliveira ML, Vauthey JN, Dindo D, Schulick RD, de Santibanes E, Pekolj J, Slankamenac K, Bassi C, Graf R, Vonlanthen R, Padbury R, Cameron JL and Makuuchi $\mathrm{M}$ : The Clavien-Dindo classification of surgical complications: five-year experience. Ann Surg 250: 187-196, 2009.

$17 \mathrm{Lu} \mathrm{X,} \mathrm{Zhao} \mathrm{H,} \mathrm{Yang} \mathrm{H,} \mathrm{Mao} \mathrm{Y,} \mathrm{Sang} \mathrm{X,} \mathrm{Miao} \mathrm{R,} \mathrm{Xu} \mathrm{Y,} \mathrm{Du} \mathrm{S,}$ $\mathrm{Xu} \mathrm{H}$, Chi T, Yang $\mathrm{Z}$, Zhong $\mathrm{S}$ and Huang J: A prospective clinical study on early recurrence of hepatocellular carcinoma after hepatectomy. J Surg Oncol 100: 488-493, 2009.

18 Shah SA, Greig PD, Gallinger S, Cattral MS, Dixon E, Kim RD, Taylor BR, Grant DR and Vollmer CM: Factors associated with early recurrence after resection for hepatocellular carcinoma and outcomes. J Am Coll Surg 202: 275-283, 2006.

19 Schulze K, Gasch C, Staufer K, Nashan B, Lohse AW, Pantel K, Riethdorf $\mathrm{S}$ and Wege $\mathrm{H}$ : Presence of EpCAM-positive circulating tumor cells as biomarker for systemic disease strongly correlates to survival in patients with hepatocellular carcinoma. Int J Cancer 133: 2165-2171, 2013. 
20 Fan ST, Yang ZF, Ho DW, Ng MN, Yu WC and Wong J: Prediction of posthepatectomy recurrence of hepatocellular carcinoma by circulating cancer stem cells: a prospective study. Ann Surg 254: 569-576, 2011.

21 Senthilnathan S, Memon K, Lewandowski RJ, Kulik L, Mulcahy MF, Riaz A, Miller FH, Yaghmai V, Nikolaidis P, Wang E, Baker $\mathrm{T}$, Abecassis M, Benson AB, 3rd, Omary RA and Salem R: Extrahepatic metastases occur in a minority of hepatocellular carcinoma patients treated with locoregional therapies: analyzing patterns of progression in 285 patients. Hepatology 55: 14321442, 2012.

22 Yang Y, Nagano H, Ota H, Morimoto O, Nakamura M, Wada H, Noda T, Damdinsuren B, Marubashi S, Miyamoto A, Takeda Y, Dono K, Umeshita K, Nakamori S, Wakasa K, Sakon M and Monden M: Patterns and clinicopathologic features of extrahepatic recurrence of hepatocellular carcinoma after curative resection. Surgery 141: 196-202, 2007.

23 Ochiai T, Ikoma H, Okamoto K, Kokuba Y, Sonoyama T and Otsuji E: Clinicopathologic features and risk factors for extrahepatic recurrences of hepatocellular carcinoma after curative resection. World J Surg 36: 136-143, 2012.

24 Jun L, Zhenlin Y, Renyan G, Yizhou W, Xuying W, Feng X, Yong X, Kui W, Jian L, Dong W, Hongyang W, Lehua S, Mengchao W and Feng S: Independent factors and predictive score for extrahepatic metastasis of hepatocellular carcinoma following curative hepatectomy. Oncologist 17: 963-969, 2012.

25 Mikuriya Y, Tashiro H, Kuroda S, Nambu J, Kobayashi T, Amano H, Tanaka Y and Ohdan H: Fatty liver creates a pro-metastatic microenvironment for hepatocellular carcinoma through activation of hepatic stellate cells. Int J Cancer 136: E3-13, 2015.

26 Nishikawa M: Reactive oxygen species in tumor metastasis. Cancer Lett 266: 53-59, 2008.
27 Agopian VG, Harlander-Locke M, Zarrinpar A, Kaldas FM, Farmer DG, Yersiz H, Finn RS, Tong M, Hiatt JR and Busuttil RW: A novel prognostic nomogram accurately predicts hepatocellular carcinoma recurrence after liver transplantation: analysis of 865 consecutive liver transplant recipients. J Am Coll Surg 220: 416-427, 2015.

28 Llovet JM, Ricci S, Mazzaferro V, Hilgard P, Gane E, Blanc JF, de Oliveira AC, Santoro A, Raoul JL, Forner A, Schwartz M, Porta C, Zeuzem S, Bolondi L, Greten TF, Galle PR, Seitz JF, Borbath I, Haussinger D, Giannaris T, Shan M, Moscovici M, Voliotis D and Bruix J: Sorafenib in advanced hepatocellular carcinoma. N Engl J Med 359: 378-390, 2008.

29 Miyaki D, Aikata H, Honda Y, Naeshiro N, Nakahara T, Tanaka M, Nagaoki Y, Kawaoka T, Takaki S, Waki K, Hiramatsu A, Takahashi S, Ishikawa M, Kakizawa H, Awai K and Chayama $\mathrm{K}$ : Hepatic arterial infusion chemotherapy for advanced hepatocellular carcinoma according to Child-Pugh classification. J Gastroenterol Hepatol 27: 1850-1857, 2012.

30 Kawaoka T, Aikata H, Hyogo H, Morio R, Morio K, Hatooka M, Fukuhara T, Kobayashi T, Naeshiro N, Miyaki D, Hiramatsu A, Imamura M, Kawakami Y, Takahashi S, Waki K, Tsuji K, Kohno H, Moriya T and Chayama K: Comparison of hepatic arterial infusion chemotherapy versus sorafenib monotherapy in patients with advanced hepatocellular carcinoma. J Dig Dis 16: 505-512, 2015.
Received March 2, 2017

Revised March 21, 2017

Accepted March 24, 2017 